\title{
FREE POLICY IN PUBLIC LIBRARY SYSTEM IN CHINA: SUBJECT, CRITERIA AND METHODOLOGY
}

\author{
Li Jia \\ International College, Krirk University, Thanon Ram Intra, Khwaeng Anusawari, Khet Bang Khen, Krung Thep, \\ Maha Nakhon10220, Thailand
}

Abstract - On the day of 2011, February 10, the ministry of culture and ministry of finance in China jointly issued a public policy document entitled as «on promoting free opening of national art galleries public libraries and cultural center stations». This document clearly declared the basic objective and goal of free policy in these public service domains as: till the end of the year 2011, all public libraries in China should follow the free policy on entrance fee, using of public space and facilities and basic services.

This current study traced the theoretical extrapolations of assessment of public library system and its significance to the continuing service improvement and nation building.

Following a qualitative research design, this paper focused on the enumeration of three key components of public library assessment system in China, namely subject, criteria and methodology. Western historically influential theories were referred to. However, the contextualization of these theoretical thoughts into a specific (eastern and socialismdominated) national culture, ideology, praxis and social milieu would be high lightened in the theoretical constructs and orientation of this paper. Towards the end this paper draws on conclusion by using a case study of Liu Zhou City Library(LZCL) in adopting the free policy. The objective of this paper is to introduce to librarian practitioners who are facing the same plights a workable model in constructing a nimble and fit assessment system based on its own social scenario.

Keywords - Public Library System, Free Policy, China

\section{INTRODUCTION}

In 2011, February 10, the ministry of culture and the ministry of finance of China jointly issued the document of «on promoting free opening of national art gallery, public libraries and cultural center (station) ». In this document, it was clearly specified the scope, content and objectives of the free policy of public libraries: Towards the end of 2011, all the public libraries in China should realize these goals in their service:

1. Absolutely free to every citizen,

2. All the facilities within the domain of public areas should be open to the public with no charge.

3. The basic services should be provided to the public free of charge.

Further, this document suggests four strategies in servicing these goals as:

1. Change some services items from "service with a charge fee" to "no charge"

2. Decrease the rate of charge on "non-basic" services items.

3. Increase the intensity of the propaganda of free policy to the public.

4. Formulate preventive plans for emergencies.

Moreover, recommendations in this document for establishing the institutional mechanism of executing this free policy are shown in figure 1 . 
Figure 1 Institutional Mechanism of Executing Free Policy

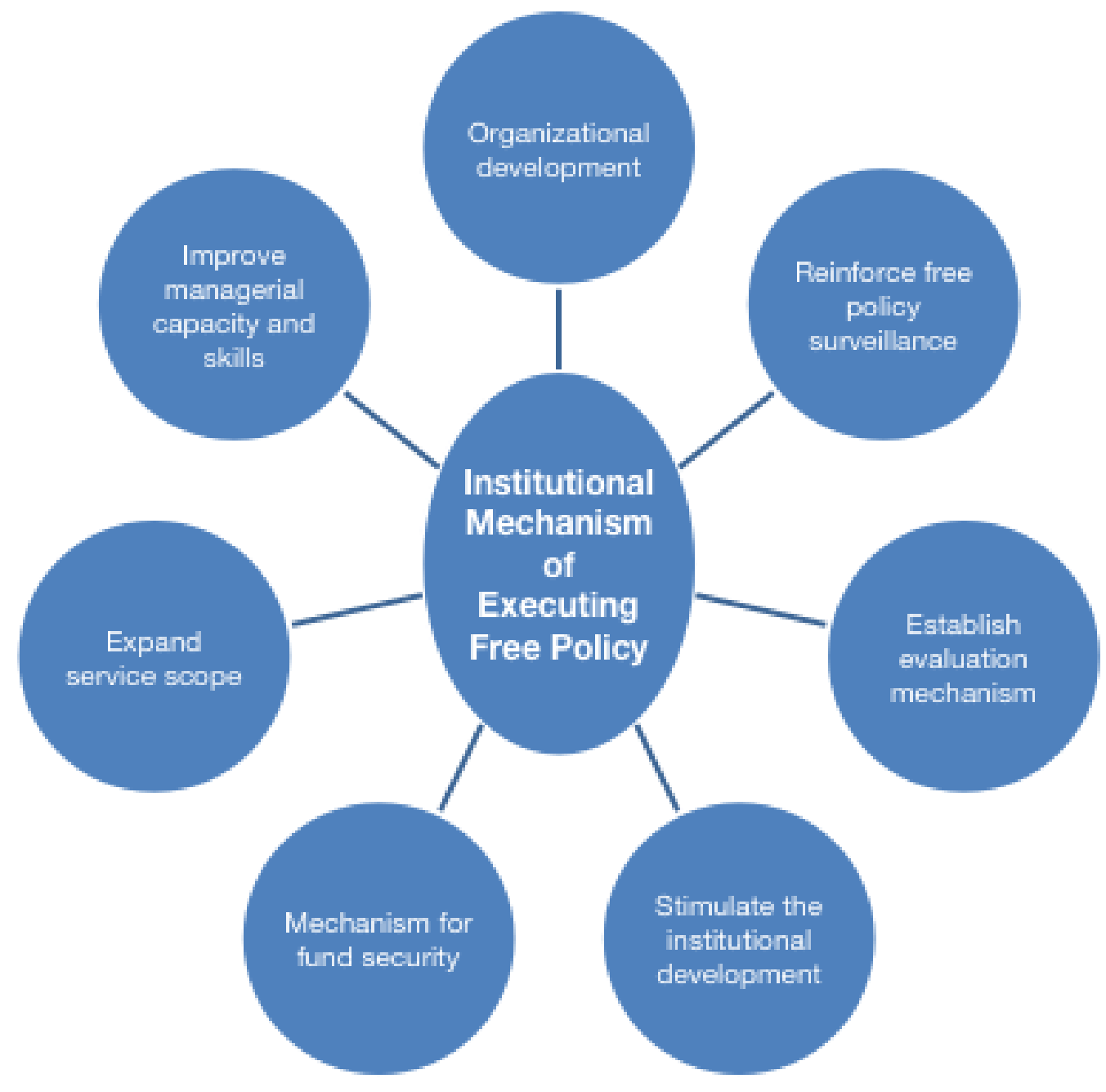

Later on, the ministry of finance issued the documents of « on reinforcing the securing of fund-allocations in service of free policies of art gallery, public libraries, and cultural center (stations) ». This document requests every level of the ministry of finance to reinforce the fund security in executing the free policy, established a well- fledged fund-security system. It also clarifies the rules, responsibility and fund assistance criteria in service of the free policy execution.

\section{SIGNIFICANCE OF THE TWO DOCUMENTS ON PUBLIC LIBRARIES FREE POLICY IN CHINA}

1) These two documents provided with the foundation to mandates free policy at the state legislation level.

2) These two documents present a milestone in China's endeavors towards improving its public cultural service infrastructure, which should be founded on the principles of publicity, egalitarianism, fundamentality and convenience. 


\section{International Journal of Engineering Applied Sciences and Technology, 2021 \\ Vol. 6, Issue 1, ISSN No. 2455-2143, Pages 21-28 \\ Published Online May 2021 in IJEAST (http://www.ijeast.com)}

Figure 2 Principles of Modern Public Library

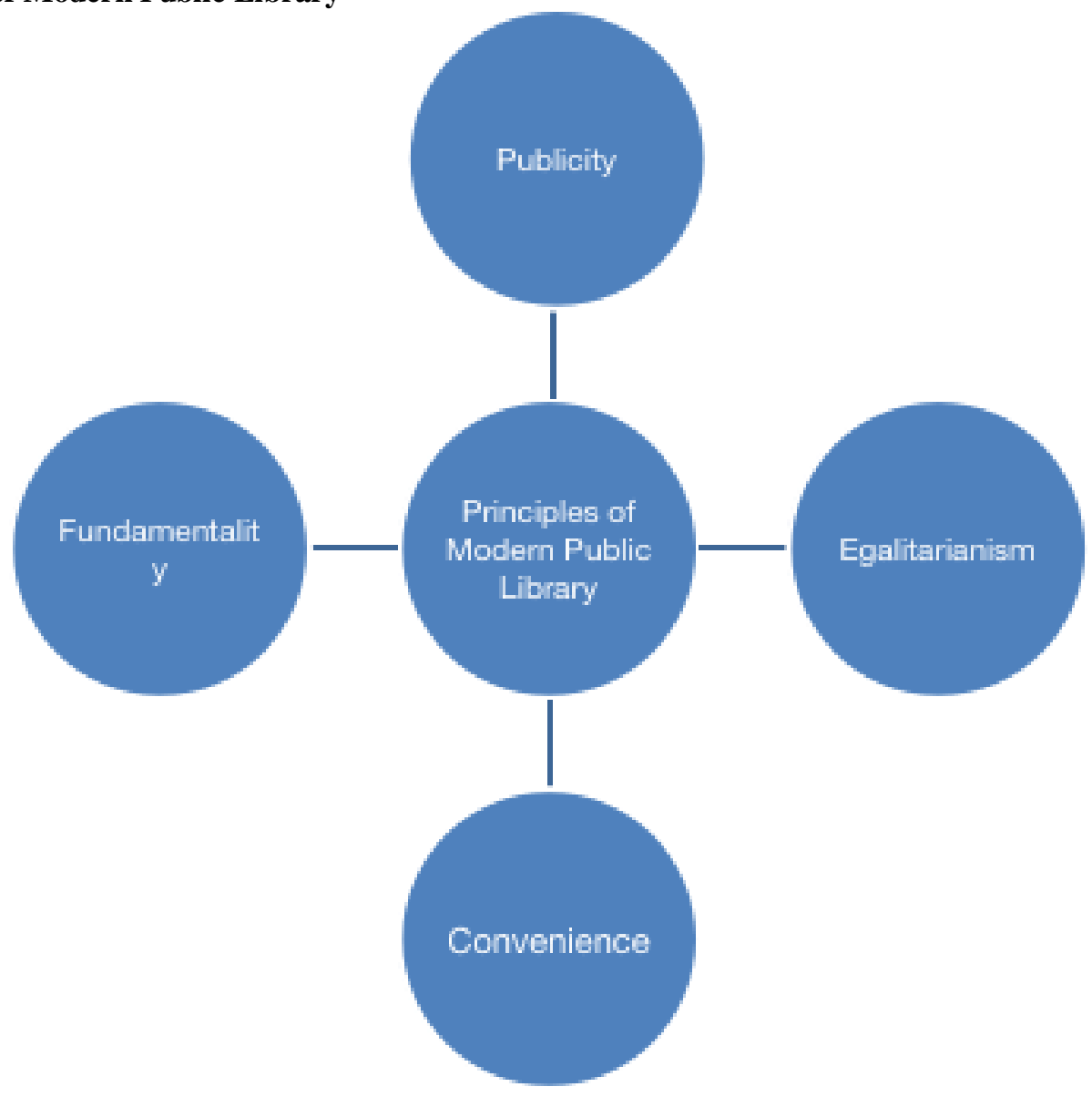

Global wise, it's the historical trend for public libraries to be open free in service to the public as the reincarnation of the serviceability as the foundation of modern library spirits.

\section{THE NECESSITY OF FREE POLICY EVALUATION}

The free policy of public libraries in China, at the hierarchical level of the state the corresponding institutions must formulate their own policies in facilitating and executing this nation-wise public policy legislation. However,

1) How effectively and efficiently each region has been carrying out this policy?

2) What is the impact of this policy on the regional community development?

3) Has the policy been followed in the aims of servicing the public or as the tool of "political capital gain" in a superficial and empty "shell" to fool the people?

These questions can only be answered after a systematic and scientific evaluation process.

\section{THE SIGNIFICANCE OF PUBLIC LIBRARY FREE POLICY EVALUATION}

Policy evaluation is the evaluation subject assess and evaluate the output and input of executing a policy, in the aim of discovering if the anticipated goals and objectives have been achieved, which provides the data and foundation for policy modification, policy improvement and new policy formulation(Popper,1962).

Firstly; through policy evaluation the effectiveness of the policy execution can be assessed, which includes if the assessing content, the strategies and developmental mechanism have achieved the anticipated goals.

Secondly, it can provide the policy adjustment with important data. The free policy application is a multi-faceted and multi-leveled continuous dynamic process. Due to regional and cultural difference, the issues and problems encountered will be inevitable. Evaluation can identify such deviations.

Thirdly, it can facilitate the optimization of investment and current available property. How much it is needed to invest? How to invest? Through policy evaluation it can discover the optimal sequence and proportion to the total amount, which leads to ideal end outcomes. 


\section{International Journal of Engineering Applied Sciences and Technology, 2021 \\ Vol. 6, Issue 1, ISSN No. 2455-2143, Pages 21-28 \\ Published Online May 2021 in IJEAST (http://www.ijeast.com)}

Fourthly, it can identify the responsibilities of each stakeholder. The execution involves different institutions including the library, cultural administration department, finance departments, etc. How to identify each party's responsibility scope? Evaluation provides the answer to this aspect.
Fifthly, policy evaluation is an important strategy in boosting up the quality of the service of the library.

\section{FREE POLICY EVALUATION SYSTEM}

Figure 3 shows the components of the free policy evaluation system.

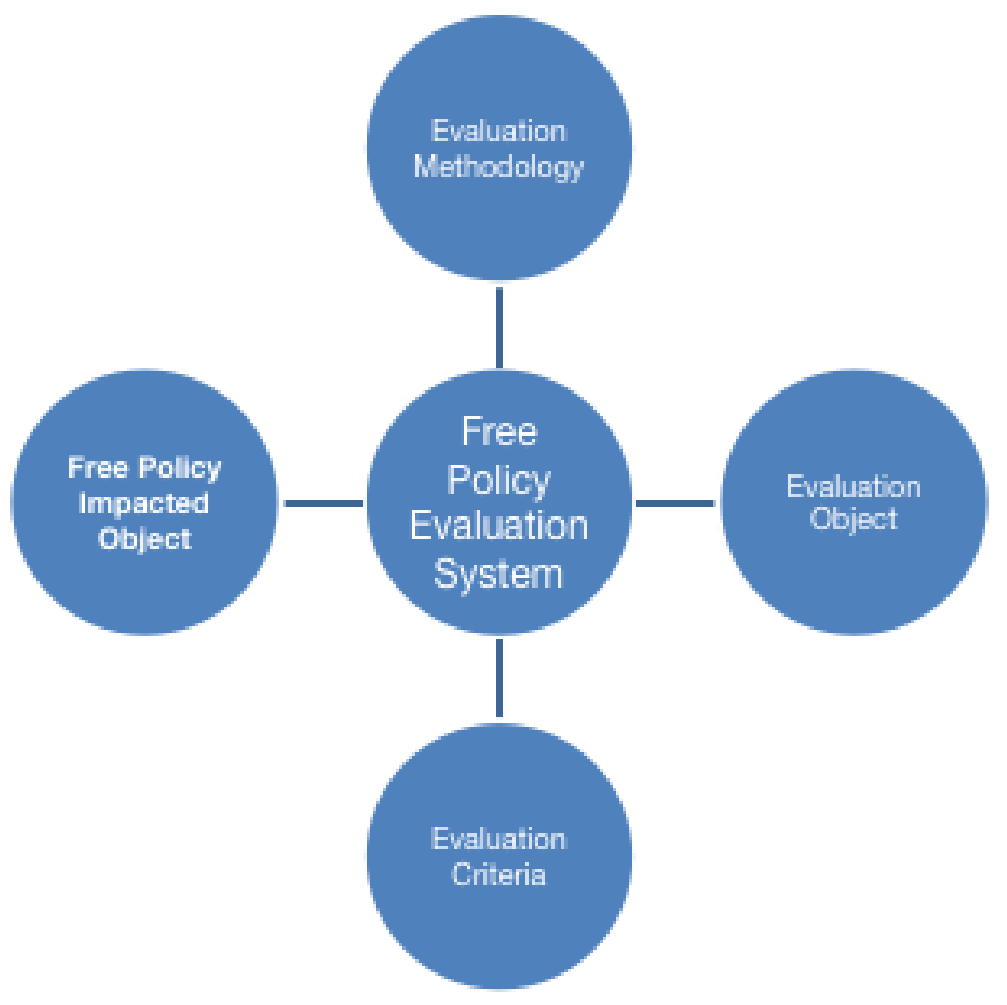

Figure 3 Free Policy Evaluation System

\subsection{Free Policy Impacted Object}

This paper identifies the library, the stuff and the readers as the impacted object of the free policy.

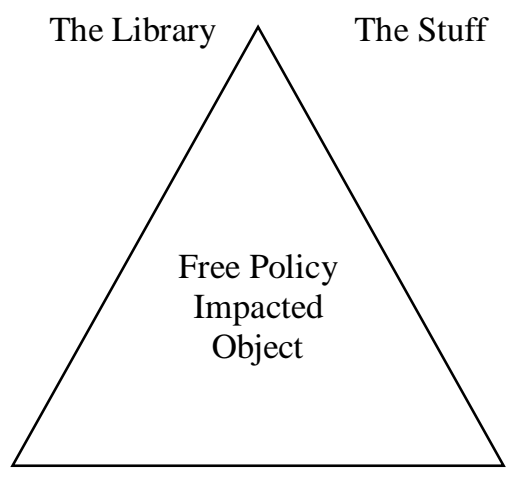

The Readers

Figure 4 Free Policy Impacted Object

\subsection{Subject}

Traditional practice in constructing of evaluation team consists of two groups of experts

a. insider: from governmental agencies

b. outsider: from outside the governmental agencies as independent evaluator.

In this paper, I would like to suggest amore multifaceted constitution of the evaluation team which will avoid the bias and limitation of single evaluation status. The constitution evaluation team should be composed by such stakeholders as the library, the readers, corresponding governmental administration agency, independent surveillance institutes social organization and professional policy evaluation agencies. 


\section{International Journal of Engineering Applied Sciences and Technology, 2021 \\ Vol. 6, Issue 1, ISSN No. 2455-2143, Pages 21-28 \\ Published Online May 2021 in IJEAST (http://www.ijeast.com)}

\section{Figure 5 Free Policy Evaluation Subject}

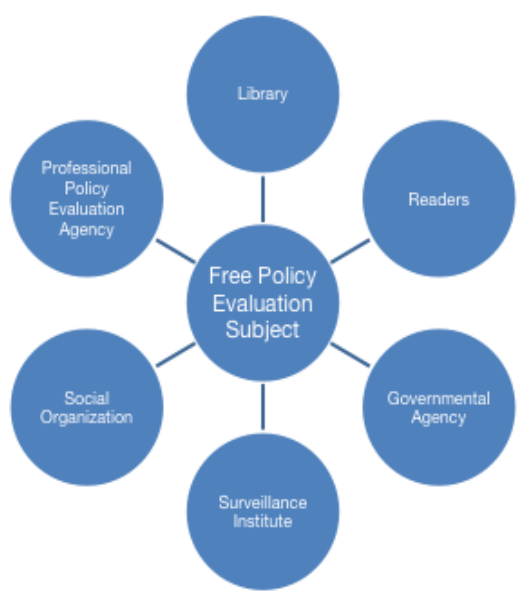

\subsection{Evaluation Criteria}

The choice, arrangement and sequence of evaluation will directly lead to the credibility of such evaluation. By nature, as a process of exploring, reasoning, featuring and modifying a policy, all the reasonability and credibility starts from identifying the evaluation criteria. This paper suggests the three criteria as policy effectiveness, policy efficiency, policy impact as shown in figure 5 .

Policy Impact

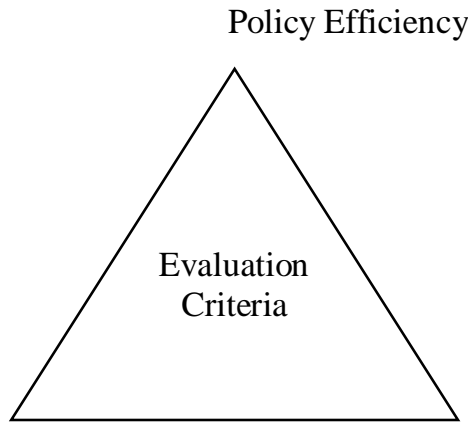

Policy Effectiveness

\section{Figure 6 Evaluation Criteria}

Policy efficiency: Mainly through the efficiency of administration, namely to what extent the corresponding executors of the policy have done their tasks.

Policy effectiveness: Through the comparison between the achieved and anticipated outcomes. This aspect reflects how policy impacted object (Library, stuff, readers) have benefited from the policy.

Policy impact: Mainly focuses on evaluate indirect social impact on the policy object, including social equality, sustainable development, etc.

\subsection{Evaluation Methodology}

This paper suggest a triangular model as a combined approach towards data collection and analysis, which is composed of self-evaluation, outer-evaluation and expertevaluation, as shown in figure
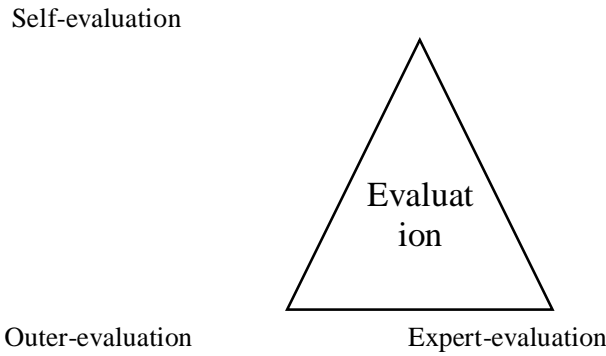

Figure 7 Evaluation Methodology

Self-evaluation: is carried out by library and government agencies to self-assess the aspects of three criteria as discussed above.

Outer-evaluation: is carried out through the social public as how the policy has been experienced by themselves.

Expert evaluation: is organized by professional evaluation institutions, surveillance institution and social organizations using structural data collection through records investigation, on-site observation, and random-sampling questionnaires to be answered from the readers and storm-brain session with the library stuff. All the data will be solicited on 1-5 Likette Scale, which is: 5-exelent, 4-good, 3-average, 2-not good, 1-bad. This data will be further going through statistic treatment such as Pearson Product Correlation Coefficient, to identify the correlation among them and solicit the causes of undesirable outcomes or behaviors.

\section{A CASE STUDY OF LIU ZHOU CITY LIBRARY IN ADOPTING FREE POLICY}

\subsection{Historical Background in China}

The free policy has been pioneered by several economic developed region even as early as 2003.In 2003, Zhang Zhou City Library started free policy in its general section reader's room. In 2007, Zhang Zhou City Library started free policy on all its storage. Any citizen could borrow books by presenting a Zhang Zhou citizen ID.

In Dec 11, 2007, Zhe Jiang Provincial Library became the first provincial State Library that adopted free policy in China. However, in the economic under-developed regions, the free policy has been a big challenge for local libraries with financial deficiency. Here after I introduced the practice of Liu Zhou City Library (LZCL) in adopting this policy. 


\section{International Journal of Engineering Applied Sciences and Technology, 2021 \\ Vol. 6, Issue 1, ISSN No. 2455-2143, Pages 21-28 \\ Published Online May 2021 in IJEAST (http://www.ijeast.com)}

\subsection{The City and the Library}

Liǔzhōu (Chinese: 柳州; Zhuang: Liujcouh) is a prefecture-level city in north-central Guangxi Zhuang Autonomous Region, in southern China. The prefecture's population was $3,758,700$ in 2010 , including $1,029,946$ in the built up area made of 4 urban districts. Its total area is $18,777 \mathrm{~km}^{2}$ and $667 \mathrm{~km}^{2}$ for built up area.

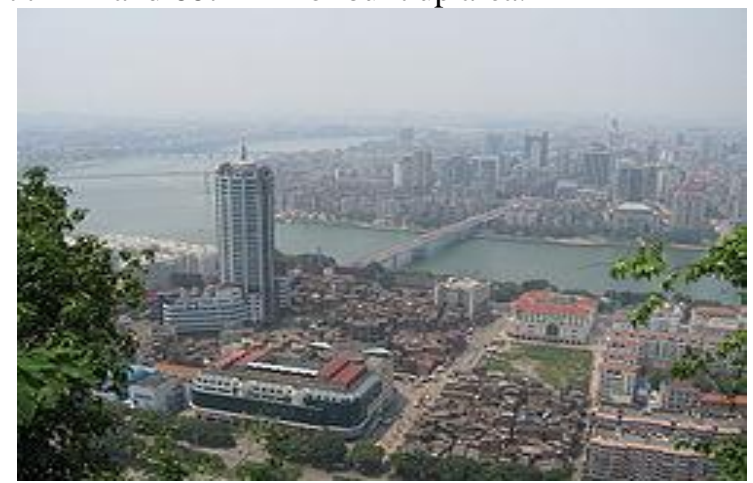

Figure 8 Liǔzhōu Picture

Liuzhou is the second largest city in Guangxi and is the region's industrial center. According to statistics issued by the Liuzhou government in 2009, the city's GDP was 103.2 billion yuan.

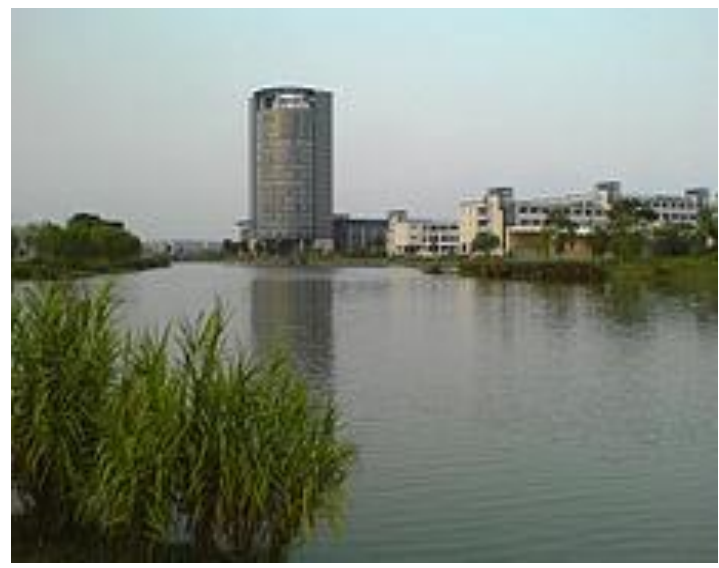

Figure 9 LZCL main Building

Located in a 14 stories and 148 feet $(106 \mathrm{~m})$ tall building, LZCL in total had a paper-based collection of about 6.98 million volumes on 10 June 2010, on top of multi-media facilitates and digital collections.

\subsection{Ideological Preparation}

The library administration boosted up the understanding of this policy to the stuff by expert seminars and online newsletter through local -network. The meantime it used internet, medias, and library bulletin to promote the civilian's awareness of such policy and its progress in LZCL.

\subsection{Actions}

6.4.1. Exempt charges from most of the services

In service to the free policy, it started steps since as early as 2004 when it applied free policy to all juveniles. In 2006 February, it exempted maintenance charge for senior citizen (60 above).

From 2011,April, it applied free policy to all Liu Zhou citizens, earlier than the specified deadline(end of 2011). On top of exemption from basic material charge, yearly renewal charge , multi-media internet fee, it also apply free charge on such services as: book/ magazine borrowing, basic consultation and research, e-material browsing, governmental administration information research, public seminars, exhibitions, free public trainings, cinema for children, basic research facilitation, etc.

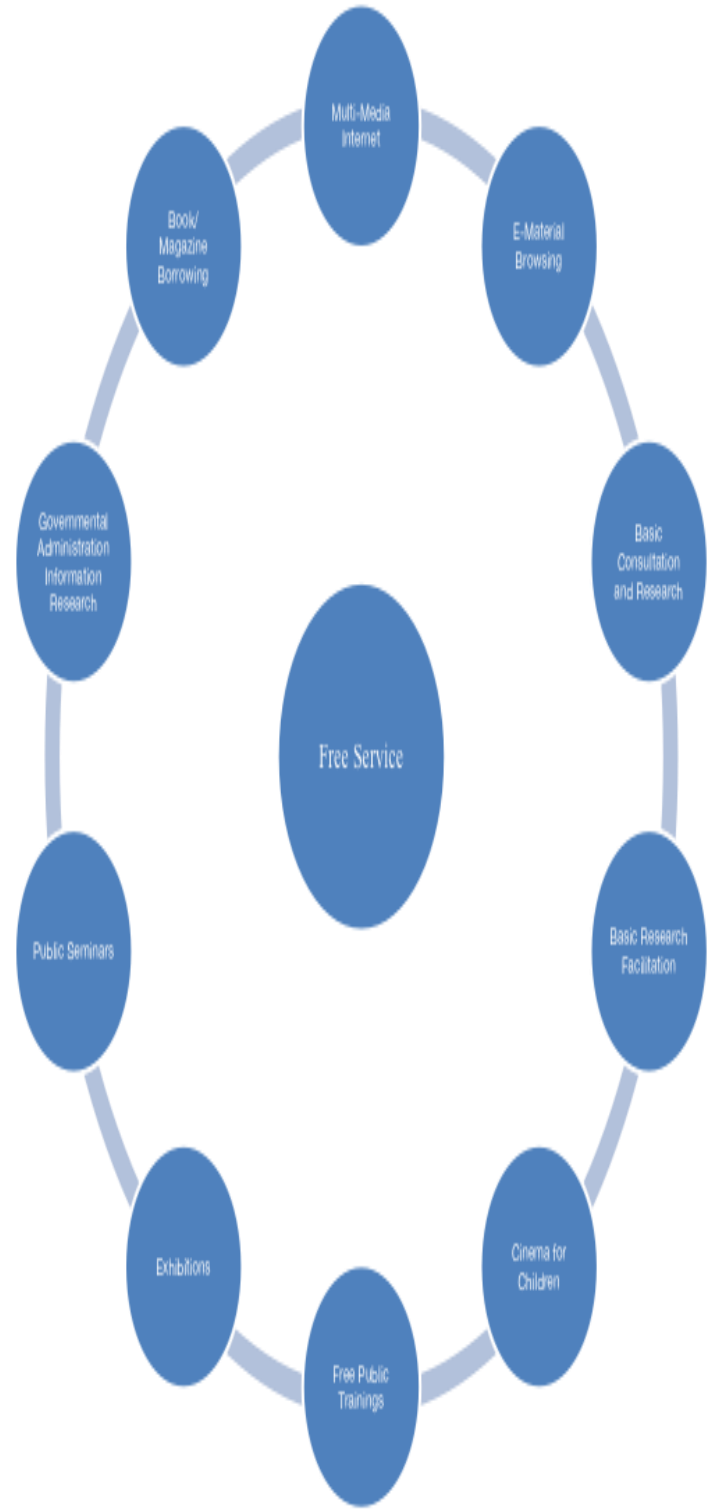

Figure 10 Free Service at LZCL 


\section{International Journal of Engineering Applied Sciences and Technology, 2021 \\ Vol. 6, Issue 1, ISSN No. 2455-2143, Pages 21-28 \\ Published Online May 2021 in IJEAST (http://www.ijeast.com)}

6.4.2. Adjust book purchase proportion.

Through maintaining the staple proportion as books on tradition media (paper), it switched from e-book purchasing to subscribe to on-line data/paper collection.

It also adjusted the proportion of audio-materials, newspaper, local histographical material, and increased purchasing on children books, since the free policy brought us a bigger component of children readers. In 2011, it bought 10,000 plus books for children.

\subsubsection{Service Scope/Methodology Innovation}

It organized 153 public activities in 2011, in the forms as World Reader's Day, Literature Seminars, Service Promotion Week, etc. The World Reader's Day actuated 20,000 participants and the 19 seminars from experts and well-known scholars attracted 7,000 participants.

\section{CONSIDERATIONS}

From above analysis, the researcher would further post four considerations for further scholarly as well as managerial research for enhancing the service of the public library in the context of free policy.

\subsection{Capital security}

This involves the question of whether some charges (such as deposit and penalty) should also be exempted and its repercussions on the operation of the library.

\subsection{Instant financial support from government agencies}

Table 1. The Comparison of the Monthly New Readers Before and After the Free Policy

\begin{tabular}{|l|l|l|}
\hline Period & $\begin{array}{l}2011 \\
\text { Jan.-April }\end{array}$ & $\begin{array}{l}2011 \\
\text { May-Dec. }\end{array}$ \\
\hline $\begin{array}{l}\text { Amount of } \\
\text { New } \\
\text { Readers }\end{array}$ & $434 /$ month & $735 /$ month \\
\hline $\begin{array}{l}\text { Increasing } \\
\text { Rate }\end{array}$ & n/a & $69 \%$ \\
\hline
\end{tabular}

Table 2. The Comparison of Monthly Transactions Before and After the Free Policy

\begin{tabular}{|l|l|l|}
\hline Period & $\begin{array}{l}2011 \\
\text { Jan.-April }\end{array}$ & $\begin{array}{l}2011 \\
\text { May-Dec. }\end{array}$ \\
\hline $\begin{array}{l}\text { Transaction } \\
\text { Amount }\end{array}$ & 32337 & 44641 \\
\hline $\begin{array}{l}\text { Increasing } \\
\text { Rate }\end{array}$ & $\mathrm{n} / \mathrm{a}$ & $38.05 \%$ \\
\hline
\end{tabular}

Beside the increasing numbers of readers and transactions, the material consumption, maintenance, and replacement, such as computer up-dating and audio players replacement and repair, all need a robust and instant financial support from corresponding state finance agency.

7.3 The training of the stuff and new talents joining the service team

From 2007, the recruitment has been open only to bachelors holders at LZCL. In 2011, it had 3 stuff with Masters Degree in librarian science recruited. However, how to keep the current human resource up-to-date with the global knowledge innovation is still a challenge.

7.4 Reconsideration of the relation between the stuff and the readers, and among the readers

Since the adoption of free-policy, more homeless people and wonders flooded into the library, which caused the new concern of how to balance these relationships between the stuff and the readers, and among the readers in the context of more under privileged groups of the society being the beneficiary of this free policy(Carter,1982).

\section{CONCLUSION}

Every public library in China has already adopted this free policy as stipulated by the corresponding legislation as of the year 2021. This scenario has provided the civilian with greater accessibility towards the collection which were hindered to be achieved by various reason, among which the most important is financial concern. This paper concludes with the necessity to evaluate to what extent this free policy has been working for its anticipated goals by applying the suggested evaluation system as presented in this paper. This evaluation system will provide the basic monitoring surveillance to get the feedback in real time and modify the policies in achieving the optimal outcomes which were targeted by the state in the aims of servicing the public.

\section{REFERENCE}

1 Exceeding expectations: Achieving professional by getting research into practice. Paper presented at the Conference of the Library Association of New Zealand (LIANZA) NA, 15-18 Oct 2000.

2 Booth, A., Brice, A. (2004). Why evidence-based information practice? In Booth, A., Brice, A. (Eds.), Evidence-based information professionals: a handbook. (pp. 1-12). London : Facet Publishing.

3 Booth, A. (2004). Formulating answerable questions. In Booth, A., Brice, A. (Eds.), Evidence-based information professionals: a handbook. (pp. 61-70). London : Facet Publishing. 


\section{International Journal of Engineering Applied Sciences and Technology, 2021 \\ Vol. 6, Issue 1, ISSN No. 2455-2143, Pages 21-28 \\ Published Online May 2021 in IJEAST (http://www.ijeast.com)}

4 Booth, A., Brice, A. (2004). Appraising the evidence? In Booth, A., Brice, A. (Eds.), Evidence-based information professionals: a handbook. (pp. 104-118). London : Facet Publishing.

5 Booth, A. (2004). Evaluating your performance. In Booth, A., Brice, A. (Eds.), Evidence-based information professionals: a handbook. (pp. 127-137). London : Facet Publishing.

6 Brice, A., Hill, A. (2004). A brief history of evidencebased practice. In Booth, A., Brice, A. (Eds.), Evidencebased information professionals: a handbook. (pp. xx). London : Facet Publishing.

Carter, Jane Robbins.(1982).

Public librarianship: a reader . Littleton:Libraries Unlimited, Inc.

8 Cotter, L., Harije, L., Lewis, S., Tonnison, I. (2006). Adding SPICE to a Library Intranet Site: A Recipe to Enhance Usability. Evidence Based Library and Information Practice, 1, 3-5

9 Eldredge, J. (2004). How good is the evidence base? In Booth, A., Brice, A. (Eds.), Evidence-based information professionals: a handbook. (pp. 36-48). London : Facet Publishing.

10 Genoni, P., Haddow, G., Ritchie, A. (2004). Why don't librarians use research? In Booth, A., Brice, A. (Eds.), Evidence-based information professionals: a handbook. (pp. 49-60). London : Facet Publishing.

11 Hallam, G. (2008). Evidence Based Library and Information Practice (EBLIP). Workshop held by Prof. Gillian Hallam at Stuttgart Media University: Summer School, $19-21$ Jun 2008.

12 Koufogiannakis, D., Crumley, E. (2004). Applying evidence to your everyday practice. In Booth, A., Brice, A. (Eds.), Evidence-based information professionals: a handbook. (pp. 119-126). London : Facet Publishing

13 Popper, K. (1962). The open society and its enemies. London, Routledge \& Kegan Paul.

14 Singer Gordon, Rachel (Date unknown). Publish, don't perish. Retrieved October 19, 2008 from: http://info.emeraldinsight.com/librarians/writing/publish - index.htm

15 University of Alberta Learning Services (Ed.). Evidence Based Library and Information Practice. Retrieved $\begin{array}{llll}\text { October } & 19, & 2008 & \text { from: }\end{array}$ http://ejournals.library.ualberta.ca/index.php/EBLIP
16 Winning, A. (2004). Identifying sources of evidence. In Booth, A., Brice, A. (Eds.), Evidence-based information professionals: a handbook. (pp. 71-88). London : Facet Publishing. 